\title{
Percutaneous Ultrasound Guided Drainage of Prostatic Abscess in a Dog
}

\author{
Rahul Kumar Udehiya', Dayamon David Mathew ${ }^{1}$, Vinod Kumar², Naresh Kumar Singh ${ }^{1, *}$
}

\begin{abstract}
A 7 year old male German shepherd dog presented with a history of blood in urine at hourly intervals having difficulty in defecation as well. Moreover, it was also loosing body weight during the past few months. Upon, ultrasonography it was observed as prostatic enlargement and diagnosed as prostatic abscess. Subsequently, the treatment went along was with gentamicin irrigation of the abscess after percutaneous drainage under ultrasound guidance and with systemic antimicrobial therapy. Excellent recovery was observed with no further complications seen or reported up to six months following the treatment.

Key words: Abscess, Ultrasound, Prostate, Gentamycin, Dog.
\end{abstract}

\section{INTRODUCTION}

Common problems affecting the canine prostate are benign enlargement, prostatitis, abs cessation, prostatic cysts, neoplasia, idiopathic hemorrhage and displacement into ruptures or hernias. ${ }^{1}$ Development of abscess inside the prostate is a rare occurrence in dog and its diagnosis is usually difficult as the clinical sign are non-specific. The etiology for prostatic abscess may be as a result of bacterial contamination spreading from another part of the urinary tract, by hematogenous route, or from cysts that become secondarily infected. ${ }^{2}$ Ultrasonography and cytological evaluation of the aspirate are useful diagnostics for confirmatory diagnosis of prostatic abscess. ${ }^{3}$ Various treatment modalities in combination with antibiotic therapy have been proposed for prostatic abscess in dogs and cats viz. surgical resection, ${ }^{4}$ intracapsular prostatic omentalization ${ }^{5}$ and percutaneous drainage. ${ }^{3}$ This article describes the use of ultrasound for diagnosis of prostatic abscess and its management through ultrasound guided drainage and subsequent gentamicin irrigation combined with systemic antibiotic therapy.

\section{History and clinical findings}

A 7 year old dog, $40 \mathrm{~kg}$ body weight, male German Shepherd was presented with a history of blood comes out from urethra before urination in every 2-3 hr intervals (Figure 1), difficulty in defecation and weight loss since one month. The dog had been under medicinal treatment without any signs of improvement. Clinical examination revealed normal rectal temperature of $101^{\circ} \mathrm{F}$ and pink mucous membrane. Pulse and respiration rate were 70 pulse and 60 breaths per minute respectively. Blood sample was collected on the day of presentation for hematological, biochemical analyses and prostate specific antigen test.

Hematology revealed neutrophilia and leukocytosis however total leukocyte count was within normal range. In serum, the blood urea nitrogen and creatinine were within the normal range as well (Table 1). All these laboratory findings were nonspecific and may occur with any prostatic diseases. The prostate specific antigen test was with in the normal range.

\section{Diagnosis and Treatment}

Radiography was performed for caudal abdomen. The lateral view of caudal abdomen revealed increase in size of prostate which was pressing the descending colon. Urinary bladder appeared to be moderately distended (Figure 2).

Ultrasonography of the abdomen using convex transducer of $5 \mathrm{MHz}$ revealed a single prostatic lesion with inner anaechoic-hypoechoic dimension measuring $2.59 \mathrm{~cm} \times 1.65 \mathrm{~cm}$ in the prostatic lobe on left side. The lesion was located at center within the prostate parenchyma. Increased echogenicity was observed at the periphery of the lesion while the centre had septal hypoechoic partition. Only the inner anechoic to hypoechoic structure was measured when determining the size of the abscess (Figure 3). Both renal cortices showed well defined corticomedullary differentiation and urinary bladder was normally distended abdomen. Based on the clinical, radiographic and ultrasonographic findings, prostatic abscess was suspected.

A fine needle aspiration was performed under ultrasound guidance for confirmation. Antibiotic sensitivity test of the aspirated sample showed

Cite this article : Udehiya RK, Mathew DD, Kumar V, Singh NK. Percutaneous Ultrasound Guided Drainage of Prostatic Abscess in a Dog. BEMS Reports. 2021;7(1):6-8.

\section{Rahul Kumar Udehiya', Daymon D Mathew ${ }^{1}$, Vinod Kumar' ${ }^{2}$ Naresh Kumar Singh ${ }^{1, *}$ \\ 'Department of Veterinary Surgery and Radiology, Faculty of Veterinary and Animal Science, Uttar Pradesh, INDIA. ${ }^{2}$ Teaching Veterinary Clinical Complex, Faculty of Veterinary and Animal Science, RGSC, Banaras Hindu University, Barkachha, Mirzapur, Uttar Pradesh, INDIA.}

*Correspondence

Dr. Naresh Kumar Singh, Ph.D

Professor and Head, Department of Veterinary Surgery and Radiology, Faculty of Veterinary and Animal Sciences, Institute of Agricultural Sciences, Rajiv Gandhi South Campus, Banaras Hindu University, Barkachha-231001, Mirzapur, Uttar Pradesh, INDIA

Phone no: +919554786939

E-mail: naresh2101@gmail.com

History

- Submission Date: 10-12-2020;

- Review completed: 17-12-2020

- Accepted Date: 21-12-2020.

DOI : 10.5530/bems.7.1.3

Article Available online

http://www.bemsreports.org

Copyright

(C) 2021 Phcog.Net. This is an openaccess article distributed under the terms of the Creative Commons Attribution 4.0 International license. 


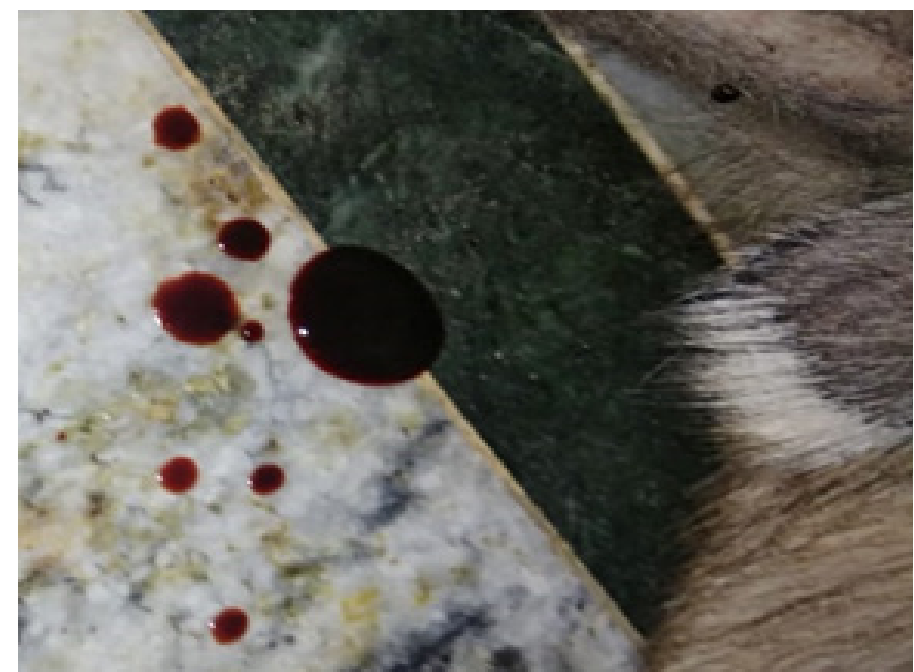

Figure 1: The blood drops comes out from urethra before urination.

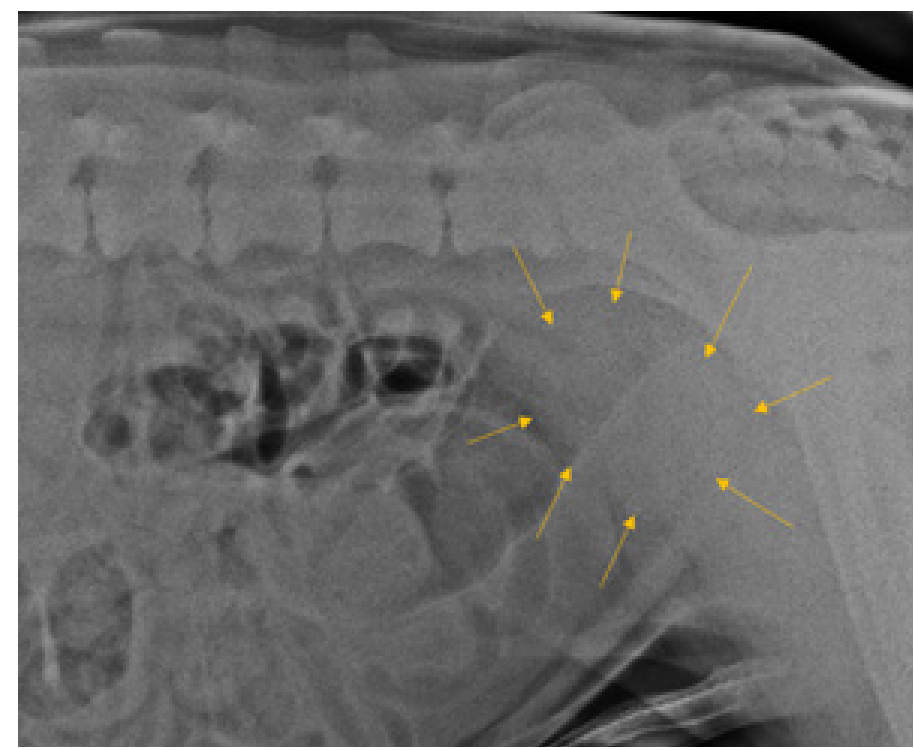

Figure 2: The lateral radiograph of caudal abdomen revealed increase in size of prostate and it pressed the descending colon.

Table 1: Haemato-biochemical and prostate specific antigen values.

\begin{tabular}{|cc} 
Parameters & Day of presentation \\
\hline Hemoglobin g\% & 15.3 \\
PCV (\%) & 45.3 \\
TEC x $10^{6} / \mu \mathrm{L}$ & 6.99 \\
TLC x $10^{3} / \mu \mathrm{L}$ & 10.8 \\
Neutrophils (\%) & 85.1 \\
Lymphocytes (\%) & 11.6 \\
Monocytes (\%) & 2.0 \\
Eosinophil’s (\%) & 1.3 \\
BUN (mg/dL) & 7.53 \\
CRTN (mg/dL) & 0.30 \\
PSA (ng/mL) & $>0.025$
\end{tabular}

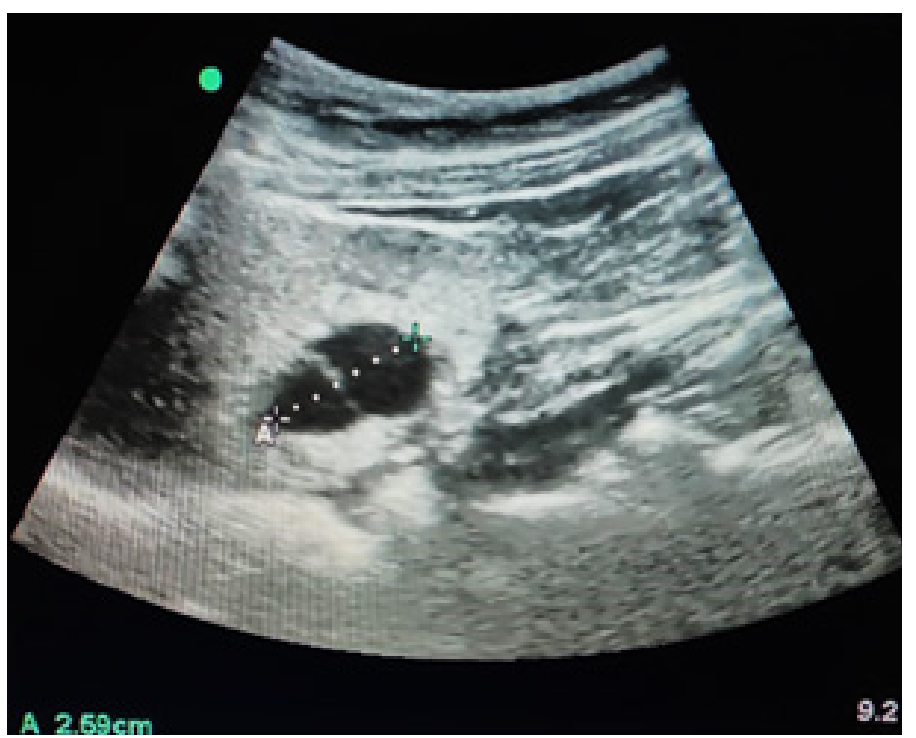

Figure 3: Large nodular lesion with cavitaryhypoechoic and anechoic material of $2.59 \times 1.65 \mathrm{~cm}$ dimension in right liver lobe in ultrasound.

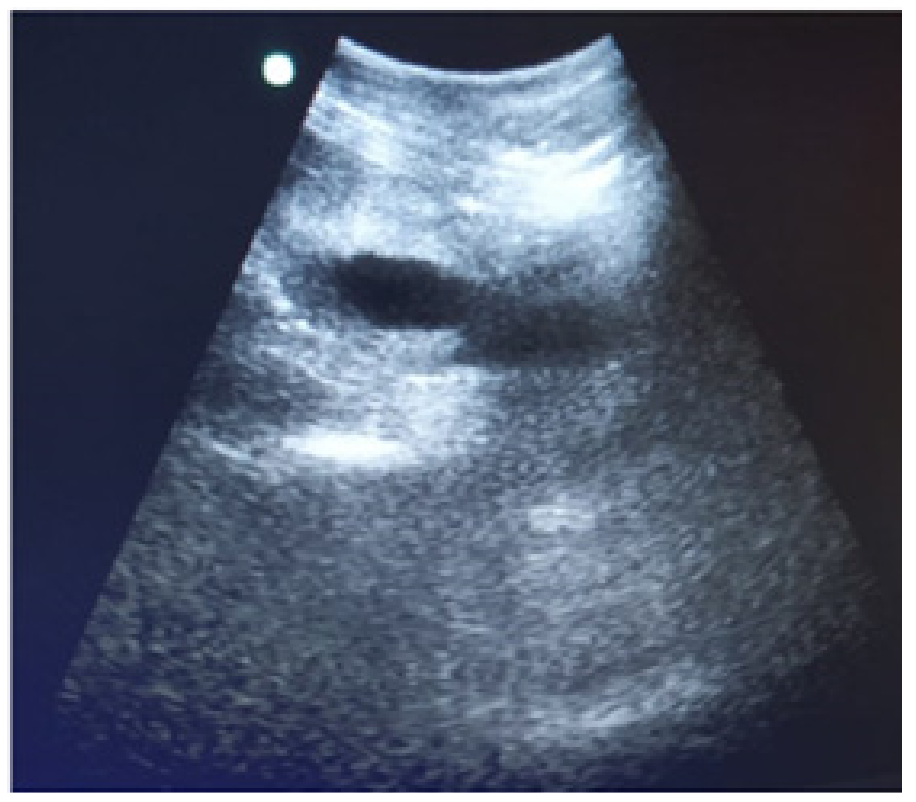

Figure 4: Reduction in the size of the abscess after one week following drainage of the abscess and gentamycin irrigation.

sensitivity of the organisms to cefotaxime, gentamicin, oflaxacine, tetracycline, ciprofloxacin, Kenamycine and resistant to amoxicillin, penicillin and erythromycin antimicrobial drugs.

The dog was prepared for ultrasound guided drainage of abscess under sedation with intravenous diazepam (@0.2mg/ $/ \mathrm{kg}$ body weight) and ketamine (@5 mg/kg body weight) after fasting for 12 hr. With the dog in ventral recumbency, the ventral abdomen wall was shaved and prepared aseptically. Under ultrasound guidance, a 16G intravenous canula, was introduced into the abscess and when the tip of the intravenous canula reached the abscess, the stylet was removed and the canula was connected to a $10 \mathrm{ml}$ sterile syringe was attached. After draining $7 \mathrm{ml}$ of pus from the abscess, $2 \mathrm{ml}$ of gentamycin was injected into the abscess through the same needle and again suck out the gentamycin then repeatedly $2 \mathrm{ml}$ of gentamycin was injected into the abscess through the same needle. The 
dog was administered Intaceftazo (ceftriaxone and tazobactum; Intas pharmaceuticals) $562.5 \mathrm{mg}$ intramuscular twice daily for 7 days; injection Melonex (Meloxicam; Intas pharmaceuticals) $2 \mathrm{ml}$ intramuscular twice daily for 7 days; $5 \mathrm{ml}$ oral suspension Alkasol (Disodium Hydrogen Citrate; Stadmed Pvt Ltd) once a day for one week and 5 mg Tablet Finax (Finasteride; Dr Reddy's Lab.) once a day oral for 5 days.

To detect treatment efficacy associated with the drainage and gentamicin irrigation, abdominal ultrasonography was performed at weekly interval. The blood from urethra before urination, difficulty in defecation and the general health of the dog returns to normal within two week following the procedure. Subsequent ultrsonographic evaluation of the prostatic abscess revealed reduction in size of abscess/ cavitary lesion at 2 weeks after drainage and gentamycin irrigation (Figure 4). The dog recovered fully and no blood from urethra before urination or other complication was recorded up to six months following the procedure. The owner also reported gradual weight gain following the treatment.

\section{DISCUSSION}

The clinical and hematological findings were non-specific and similar to those reported by Waldron, ${ }^{6}$ Lattimer, ${ }^{7}$ Hedlund ${ }^{8}$ and Boland et al. ${ }^{3}$ Anorexia, vomiting, dyschezia, ribbon like stools, dribbling of urine, prostatic shuffle, pyrexia, uremic smell from mouth, purulent urethral discharge and pain on caudal abdominal palpation were the most common clinical signs recorded in all the studies. ${ }^{9,10}$ Neutrophilia, as in this study, were also reported by other researcher along with other finding. ${ }^{11,12}$ As observed before by some researchers ${ }^{4,10}$ the biochemical values also approached near normal after treatment in the present case. However, higher levels of biochemical parameters were recorded by Bakalov et al. ${ }^{13}$ and Davidson. ${ }^{14}$ The prostate specific antigen test was within the normal range however, Chapdelaine et al. ${ }^{15}$ demonstrated that the canine prostate-specific arginine esterase (CPSE) is the most reliable marker of prostatic secretion in dogs. In present study the radiograph of the prostate revealed increased and putting pressure on the descending colon. Feeney et al. ${ }^{16}$ observed that X-ray is a choice of prostate examination in case prostatitis and to evaluate vertebral complications for hind limb stiffness. On ultrasonography, the dog had a single septal abscess located on the left prostatic lobe in the abdomen. Similar ultrasonographic findings of inner anechoic to hypoechoic structure were reported by Boland et al. ${ }^{3}$ Sindhu et al. ${ }^{11}$ and Dharmaceelan et al. ${ }^{4}$ In 2003, Boland et al. treated prostatic abscess in 8 dogs and 5 dogs with prostatic cyst by percutaneous drainage and antibiotic therapy on the basis of cytopathological examination and bacterial culture of the prostatic fluid. In the present case, $7 \mathrm{ml}$ of the pus was aspirated from the abscess under ultrasound guidance and $2 \mathrm{ml}$ of gentamicin was injected into the abscess.

\section{CONCLUSION}

Percutaneous Ultrasound Guided Drainage of prostatic abscess is efficient in dogs.

\section{ACKNOWLEDGEMENT}

The authors are thankful to Institute of Agricultural Sciences, Banaras Hindu University for rendering all help and support.

\section{CONFLICT OF INTEREST}

There is no conflict of interest among authors.

\section{ABBREVIATIONS}

Kg: Kilogram; hr: hour; ${ }^{\circ} \mathrm{F}$ : degree Fahrenheit; @: at the rate of; mg/kg: milligram per kilogram; G: Gauge; $\mathbf{m l}$ : milliliter; $\mathbf{g} \%$ : gram percent; / $\mu \mathrm{L}$ : per micro-liter; $\mathbf{m g} / \mathbf{d L}$ : milligram per deciliter.

\section{SUMMARY}

Prostatic abscess was well managed with percutaneous ultrasound guided procedure in a dog.

\section{REFERENCES}

1. Barsanti JA, Finco DR. Canine prostatic diseases. Vet Clin North Am 1986;16(3):587-99

2. Basinger RR, Robinette $C L$, Hardie EM, Spaulding KA. The prostate. The textbook of small animal surgery. Philadelphia: WB Saunders. 1993;1349-67.

3. Boland LE, Hardie, Gregory, Lamb CR. Ultrasound guided percutaneous drainage as the primary treatment for prostatic abscesses and cysts in dogs. $J$ Am Anim Hosp Assoc. 2003;39(2):151-9.

4. Dharmaceelan S, Jeyaraja K, Vishnugurubaran D, Bharathidasan M. Diagnosis and Surgical Management of Prostatic Abscess in a Dog. Intas Polivet. 2019;20(1):154-6.

5. Aissi A. Intracapsular Prostatic Omentalization: A New Technique for Management of Prostatic Abscess in Dogs: Case Report. Int J Adv Biol Biomed Res. 2018;7(1):35-8.

6. Waldron DR. Urinary Bladder In: Textbook of Small Animal Surgery, $2^{\text {nd }}$ ed. Saunders Company. 1993;1:1450-62:

7. Lattimer. The Prostate Gland. In: Veterinary Diagnostic Radiology $2^{\text {nd }}$ ed., W. B. Saunders Company. 1994;479-93.

8. Hedlund. Surgery of the Reproductive and Genital Systems. In: Small Animal Surgery; Mosby-Year Book, Inc., W. B. Saunders Company. 1997; 479-93.

9. Wallace MS. Diagnosis and medical management of canine prostatic disease. Atlantic coast veterinary conference. 2001. (http://www.vincom/p00441.htm)

10. Sindhu KR. Suppurative prostatitis in a German shepherd dog: A case report. IOSR J Agricul Vet Sci. 2014;7:25-7.

11. Sindhu, Pillai UN, Alex, Jayakumar, Joseph M. Prostatic abscess in a German shepherd dog: A case report. J Vet Anim Sci. 2011;42:68-70.

12. Kustritz MVR, Klausner JS. Prostatic diseases. Textbook of veterinary internal medicine. $5^{\text {th }}$ ed. Philadelphia: WB Saunders. 2000;1687-98.

13. Bakalov D, Goranov N, Simeonov R. Canine paraprostatic cyst: A case report. Vet Arhiv. 2004;74(1):85-94.

14. Davidson JR. Prostatic diseases of the dog. Waltham Focus. 2003;13:4-10.

15. Chapdelaine P, Dube JY, Frenette G, Tremblay RR. Identification of arginine esterase as the major androgen-dependent protein secreted by dog prostate and preliminary molecular characterization in seminal plasma. J Androl. 1984;5(3):206-10

16. Feeney DA, Johnston GR, Klausner JS, Perman V, Leininger JR, Tomlinson MJ. Canine prostatic disease-comparison of ultrasonographic appearance with morphologic and microbiologic findings: 30 cases (1981-1985). J Am Vet Med Assoc. 1987;190(8):1027-34 